\section{Transition from paediatric to adult medical services for young people with chronic neurological problems}

\section{Tuffrey, A Pearce}

Some form of structured transition to adult orientated services is required for many young people with chronic disease

A dolescence is a time of great change for all young people. As independence increases, adolescents may have difficulties in their relationships with adults and may engage in risk taking behaviour. Young people are often not registered with a general practitioner and seek medical services only when in an emergency. ${ }^{1}$ These issues also affect many youngsters with chronic disease but may have a more serious impact on future health and psychosocial functioning. Neurological conditions can have a profound effect on an adolescent's self esteem and sense of identity, ${ }^{2}$ and many young people with neurological disabilities do not have the social skills to seek out and maintain services themselves.

Transition to adult care has become a major issue across the paediatric subspecialties and will continue to present a challenge to all health care providers over the coming years. ${ }^{1}$ With improved care, diseases of childhood are becoming diseases that begin in childhood and continue into adult life. ${ }^{45}$ It has been reported internationally that the transfer to adult services for children with all chronic illnesses has been overlooked, ${ }^{6-8}$ despite increasing acknowledgement of the need..$^{510}$ Although scattered local services are being developed in a piecemeal fashion, there have been no national initiatives to date in the United Kingdom $^{11}$ and little rigorous evaluation of these services has been published. ${ }^{12}{ }^{13}$

A distinction needs to be made between the physical transfer to adult services and the process of transition from the paediatric to adult settings. Neither paediatric nor adult services may be appropriate to the needs of adolescents. $^{2}$ Adolescent medicine is a relatively new specialty in the United Kingdom, although more established in north America and Australia. ${ }^{1}$ Many paediatricians in the UK and elsewhere continue to see young people with chronic illnesses well into adult life. ${ }^{16}$ This may be because no services are available, because paediatricians are unaware of adult service provision, or because they chose to continue providing care.

\section{WHAT IS THE SIZE OF THE PROBLEM IN NEUROLOGY?}

Around $70 \%$ of young people with cerebral palsy will survive to adulthood, ${ }^{14}$ more than $50 \%$ of children with spina bifida, ${ }^{15}$ and over $25 \%$ of boys with muscular dystrophy. ${ }^{10}$ Prevalence rates for adolescents with a neurodisability are shown in table 1. As these figures show, many people with neurological diseases previously seen as paediatric are surviving to need care as adults.

\section{WHY IS TRANSITION TO ADULT SERVICES IMPORTANT?}

A recent consensus statement produced jointly by the national representative bodies of paediatricians, physicians, and family doctors in the USA states that "the goal of transition in health care for young adults with special health care needs is to maximise lifelong functioning and potential through the provision of high quality, developmentally appropriate health care services that continue uninterrupted as the individual moves from adolescence to adulthood."16 In order to achieve this goal, the following need to be considered.

Psychological aspects-Planning transition gives the message to young people

Table 1 Prevalence of chronic neurological diseases in people aged 10 to 24 years per 1000 population (US figures) ${ }^{10}$

\begin{tabular}{ll}
\hline Cerebral palsy & 1.2 \\
Epilepsy & 5.1 \\
Hearing impairment & 26.6 \\
Visual impairment & 18.7 \\
Paralysis of extremities (partial & 1.8 \\
$\begin{array}{l}\text { or total) } \\
\text { Spina bifida }\end{array}$ & 0.2 \\
$\begin{array}{l}\text { Moderate and severe learning } \\
\text { difficulties }\end{array}$ & 13.0 \\
\hline
\end{tabular}

that living into adulthood is a realistic expectation, ${ }^{10}{ }^{17}$ enhances their sense of responsibility and self esteem, ${ }^{10}$ and reinforces the notion that they are a valued member of adult society. ${ }^{18}$ Young people have the ability to adapt to new situations, and the transition to adult services can be seen as a part of the rites of passage into adulthood. ${ }^{19}$

Adult orientated care-Adult services deal more commonly with some aspects of care, such as sexual health, and may manage them better. ${ }^{17}$

Alternatives-If transition is not discussed with young people they may unilaterally decide not to continue seeing the paediatric team and be lost to all follow up. ${ }^{17}$

Research and audit-Adult clinics for rare conditions such as inborn errors of metabolism, where patients previously did not reach adult life, can also provide an opportunity to collect information on long term prognosis, monitoring, and complications, and to evaluate best practice. $^{20}$

\section{PROBLEMS WITH THE PROCESS OF TRANSITION}

There have been various barriers to successful transition, which have been well described. ${ }^{56919}$

- The paediatric team. Paediatricians may be fearful of "letting go", particularly if they feel adult services are inferior to those they have provided.

- The patient. The young person may feel abandoned by the medical team, which they may have known for most of their lives. It takes time to develop trust and confidence in a new doctor. Adult physicians may have a different style of consultation which young people may find threatening.

- The family. Parents can feel threatened by the adult environment as they lose some control and some are emotionally dependent on the paediatric services.

- The adult team. Adult physicians may have had inadequate training in paediatric conditions. They tend to be subspecialists and may be less used to multidisciplinary working. Young people may feel distressed and alienated if seen in clinics where the majority of other patients are elderly and sick.

\section{MODELS OF TRANSITION}

Three main models for transition have been described. ${ }^{16}$ The first involves transfer from a paediatric subspecialist to an adult subspecialist; the second is primary care based and is coordinated by the general practitioner; the third uses a generic adolescent health service, of which there are few in the United Kingdom. We do not know, however, which 
model works for which group of young people. ${ }^{10}$ Patients with diseases such as Duchenne muscular dystrophy are unlikely to survive beyond their early 20s, and a specific young adult clinic may be most appropriate here. Other neurological diseases have a range of life expectancies and complete transfer to an adult service is required. ${ }^{1}$ Local arrangement of services may also determine the most appropriate model. ${ }^{19}$ Although the focus of published reports is on outpatient services, transition must also include provision of appropriate inpatient services. ${ }^{9}$

After transition, services provided should be of equal quality and intensity. ${ }^{21}$ A period of concurrent care is ideal, ${ }^{17}$ although this may not be possible in all settings. Both paediatric and adult providers should be involved in the coordination and monitoring of transfer. ${ }^{17} \mathrm{~A}$ formal transition checklist including notification of key services, collation of notes, and so on can be useful. ${ }^{1}$ Clinical nurse specialists may be the best people to coordinate the transition period. ${ }^{1}$ The process should always include primary care.

\section{PLANNING THE TRANSITION}

Effective transition should include the following aspects.

- Timing. The approach should be carefully planned over a period of some time. ${ }^{6}$ Timing should be individualised to take into consideration the disease stability, the person's developmental maturity, and their educational and social situation. ${ }^{6}{ }^{17} 18$ Transfer during a period of crisis or with little warning is less likely to be successful. ${ }^{17} \mathrm{Al}$ though optimum time for transition will differ between individuals, a target transfer age may be helpful to work towards. ${ }^{1}$ Readiness for transfer can be assessed using validated questionnaires looking at the young person's knowledge of their disease, its management, and how much of the management the youngsters themselves take responsibility for. ${ }^{3}{ }^{13}$

- Multidisciplinary team. Full discussion should be had with the family and young person when planning transition $^{18}$ and all involved professionals need to be included in the process.

- Evaluation. The service should be evaluated including user feedback.

\section{THE EVIDENCE FOR SUCCESSFUL TRANSITION SERVICES FOR YOUNG PEOPLE WITH NEUROLOGICAL CONDITIONS}

Like some other chronic conditions, many neurological diseases have multisystem involvement and sequelae, so multiprofessional care is essential. Some young people will be profoundly handicapped, and employment, personal care, and social and financial support will be required in addition to medical care. This makes the transfer to adult services even more complex. There have been few studies published evaluating the transition process, and those that have were very small.

Two studies have looked at the experiences of young people where no formal transition process was in place. Warnell ${ }^{22}$ looked at a small number of families of young people with epilepsy who had previously been patients at a children's hospital. Children had transferred to adult care between 16.5 and 19 years. Seven of 10 said the transition was difficult. Predominant experiences were sadness at leaving a trusted medical team and fear of the unknown. However, eight of 10 were mostly or very satisfied with their adult neurologist and three out of 10 felt the transition was a positive move. Positive features of the adult service were less hectic and crowded waiting rooms and shorter waits. Stevenson et al compared the experiences of two age groups of young people with cerebral palsy and healthy controls. ${ }^{14}$ Employment, leisure, and social life were compared, as well as use of health and social services. The families highlighted physiotherapy as the most important health service. Epilepsy was a common reason for medical intervention, and most adolescents in the younger group had attended hospital in the previous year. Obtaining aids and equipment was difficult for the older age group. In contrast to the younger group, where the person named as knowing most about their condition apart from parents was their paediatrician, the older group said that there was no-one with this knowledge.

There have also only been a few studies which have evaluated a formal process. Sawyer et al described a pilot of the transfer of spina bifida patients to an adult service. ${ }^{23}$ The process included formation of a committee comprising professionals from both adult and paediatric services, as well as consumer representatives. They found that the compilation of a comprehensive medical record took around four hours per patient. Pretransfer interviews with the patients revealed anxieties about leaving trusted professionals and meeting new specialists with whom they had to build a relationship. There were specific fears regarding whether adequate information would be transferred. Post-transfer interviews found dissatisfaction with time delays in the family being contacted by the adult institution, a belief that follow up arrangements and reviews were insufficient in the adult service, and uncertainty about future medical care. Four of the 10 chose to continue to see a paediatrician funded through private health care.

Appleton et al and Smith et al have described clinics for teenagers with epilepsy in the United Kingdom set up in 1991 and 1997, respectively. ${ }^{24}$ One of the aims of both clinics was to facilitate the efficient transfer of patients to adult services. Both are staffed by a paediatric neurologist, an adult neurologist, and a specialist nurse. Appleton found that the teenagers' main concerns were around employment, driving, and sexual health, all of which may be poorly dealt with by a purely paediatric service. Smith noted that only $14 \%$ of the girls on anticonvulsants at the time of consultation at their teenage clinic were taking folate supplements, a situation they were able to rectify in their clinic. They also felt that the clinic's deliberate emphasis on directing the conversation towards the teenager rather than the parents was important, and the structure of the clinic, with a separate room for physical examination where they could discuss issues with the young person without the parents present, was also very valuable. Neither of these studies reported on patient satisfaction with this model or on longer term outcomes such as treatment adherence and attendance at adult clinics following the setting up of the service.

\section{CONCLUSIONS}

There is evidence that adolescent patients are not ideally served by paediatric services and that some form of structured transition to adult orientated services is required for many young people with chronic disease. There has been little published on the evaluation of services for young people with neurological conditions transferring to adult medical care. The reports that have been published do not provide the evidence enabling one to conclude whether a formal medical transition leads to a better outcome for all young people, whether one model is better than the others, or whether different models are needed for different groups of patients. Further work needs to be done on evaluating the different models so that these questions can be answered.

J Neurol Neurosurg Psychiatry
2003;74:1011-1013

\section{Authors' affiliations}

C Tuffrey, North Bristol NHS Trust, Frenchay Hospital, Bristol, UK

A Pearce, Community Child Health Department, North Bristol NHS Trust, Southmead Hospital, Bristol

Correspondence to: Dr C Tuffrey, 9 Greenhill, Neston, Corsham, Wilts SN13 9RN, UK: tuffrey@yahoo.co.uk 


\section{REFERENCES}

1 Viner R. Transition from paediatric to adult care. Bridging the gap or passing the buck? Arch Dis Child 1999:81:271-5.

2 Smith PE. The teenager with epilepsy has special needs. BM 1998;317:960-1.

3 Cappelli M, MacDonald NE, McGrath PJ. Assessment of readiness to transfer to adult care for adolescents with cystic fibrosis. Child Health Care 1999;18:218-24.

4 Rosen DS. Growing up: health care for adolescents and young adults with chronic conditions. Am J Dis Child 1992:146:901-2.

5 Viner $\mathbf{R}$. Effective transition from paediatric to adult services. Hosp Med 2000;61:341-3.

6 Sawyer SM, Blair S, Bowes G. Chronic illness in adolescents: transfer or transition to adult services. J Paediatr Child Health 1997:33:88-90.

7 McConachie H, Smyth D, Bax M. Services for children with disabilities in European countries. Dev Med Child Neurol 1997:39/suppl 76).

8 Kurtz Z, Hopkins A, eds. Services for young people with chronic disorders. London: Royal College of Physicians of London, 1996.

9 Committee Report. Committee on children with disabilities and committee on adolescence of the American Academy of Pediatrics. Transition of care provided for adolescents with special health care needs. Pediatrics 1996;98:1203-6.
10 Blum R, Garell D, Hodgman CH, et al. Transition from child-centered to adult health care systems for adolescents with chronic conditions. A position paper of the Society for Adolescent Medicine. J Adolesc Health 1993; 14:570-6.

11 Bowes G, Sinnema G, Suris JC, et al. Transition services for youth with disabilities: a global perspective. J Adolesc Health 1995: 17:23-31.

12 Scal P, Evans T, Blozis S, et al. Trends in transition from pediatric to adult health care services for young adults with chronic conditions. J Adolesc Health 1999:24:259-64

13 Betz CL. Facilitating the transition of adolescents with chronic conditions from pediatric to adult health care and community settings. Issues Compr Pediatr Nurs 1998:21:97-1 15.

14 Stevenson CJ, Pharoah PO, Stevenson R. Cerebral palsy - the transition from youth to adulthood. Dev Med Child Neurol 1997:39:336-42.

15 Hunt GM, Poulton A. Open spina bifida: a complete cohort reviewed 25 years after closure. Dev Med Child Neurol 1995:37:19-29.

16 A consensus statement on health care transition for young adults with special health care needs. Pediatrics 2002;110:1304-6.
17 Rosen DS. Transition to adult health care for adolescents and young adults with cancer. Cancer 1993;71:3411-14.

18 Watson AR, Shooter M. Transitioning adolescents from pediatric to adult dialysis units. Adv Perit Dial 1996;12:176-8.

19 Schidlow DV, Fiel SB. Life beyond paediatrics. Med Clin North Am 1990;74: 1113-20.

20 Brenton DP. The adult and adolescent clinic for inborn errors of metabolism. J Inherit Metab Dis 2000;23:215-28.

21 Savage MO, Besser GM. When and how to transfer patients from paediatric to adult endocrinologists: experience from $\mathrm{St}$ Bartholomew's Hospital, London. Acta Paediatr Suppl 1997;423:127-8.

22 Warnell $\mathbf{P}$. The transition experience of epilepsy patients/families: results of a telephone survey. Axone 1998:20:31-3.

23 Sawyer SM, Collins N, Bryan D, et al. Young people with spina bifida: transfer from paediatric to adult health care. J Paediatr Child Health 1998:34:414-17.

24 Appleton RE, Chadwick D, Sweeney A. Managing the teenager with epilepsy: paediatric to adult care. Seizure 1997:6:27-30.

25 Smith PE, Myson V, Gibbon F. A teenager epilepsy clinic: observational study. Eur J Neurol 2002;9:373-6. include a glossary explaining the terminology, and provide links to web based resources for further information. Finally, we have encouraged each author to speculate about the future, highlighting areas of potential growth and their relevance to routine clinical practice over the next decade.

We think that you will find this series both interesting and informative. It will hopefully give us all confidence in areas that we do not consider our own, enhance and enrich our clinical practice, and thereby improve the care that we give to patients with neurological disease.

J Neurol Neurosurg Psychiatry 2003;74:1013

\section{Authors' affiliations}

P F Chinnery (series editor), Department of Neurology, University of Newcastle upon Tyne, Framlington, Newcastle upon Tyne NE2 4HH, UK

C Kennard (editor), JNNP, Division of Neuroscience and Psychological Medicine, Imperial College London, Charing Cross Hospital, London W6 8RF

Correspondence to: Dr P F Chinnery; p.f.chinnery@ncl.ac.uk scientific principles behind neurology have encouraged the authors to use diagrams to help explain difficult concepts, 


\section{Mental deterioration late after head injury-does it happen? \\ N Brooks}

The relation between cognitive state after a head injury and APOE status is still ambiguous

$\mathrm{T}$ he possibility of late mental deterioration after head injury has been raised for many years, although infrequently until recently. It is now becoming quite a hot topic, with three separate and interacting strands of research and ideas. The first of the three interrelated topics is the work on genetic factors in recovery after head injury. The second is the possible relation between head injury and later onset of Alzheimer's disease. The third is the possible relation between head injury and (much) later cognitive deterioration.

There is certainly evidence to draw on in all three areas, although probably it is the former in which information is the least ambiguous, with evidence of a relation between genetic factors (APOE status) and early recovery/outcome after head injury. One problem with all these areas of research is the practical difficulty of obtaining good research data. To do so demands a prolonged longitudinal follow up of the kind that is very rarely seen; when it is seen, it is often in a military context (for example, the long term follow up of British World War II injuries reported by Newcombe ${ }^{1}$ and the American long term follow up of World War II injuries reported by Walker and others.

Evidence from those sources is ambiguous and conflicting. On the one hand, Corkin et al found mental deterioration very late after head injury in World War II missile injury survivors, reporting that the survivors in their 50 s and 60 s became simply less mentally "sharp", and this was also reflected on tests of mental function. ${ }^{3}$ Plassman et al reported a raised prevalence of Alzheimer's disease in World War II brain injured veterans many years after injury compared with controls. ${ }^{4}$ However, Newcombe, ${ }^{1}$ in an English follow up, found no evidence of mental deterioration, and was particularly impressed with the mental acuity of the brain injured soldiers whom she followed up for many years. Of course, the mental testing procedure used in those studies would now, inevitably, be thought of as relatively unsophisticated and perhaps not very sensitive.

The paper by Millar et al in this issue (pp 1047-1052) is something of a first. It is a long term follow up of cognitive status in civilians who have suffered a head injury and in whom APOE status is known. The results are, to a degree, ambiguous, showing that there is a possibility of late decline, although any decline is clearly not major and arguably it may not have been identified fully by the neuropsychological procedures employed by the authors. Furthermore, there was no clear relation to an APOE genotype. Despite the fact that the authors followed patients up for 15 to 25 years, they were very careful to point out that their cohort is still "too young" (with a mean age of 42.1 years) to assess the risk of Alzheimer's disease. Coming up with good data in this area is going to take dedicated research teams with very long term perspective. Given the exigencies of research funding, is this likely to happen?

J Neurol Neurosurg Psychiatry 2003;74:1014

\section{Author's affiliation}

N Brooks, Rehab Without Walls, 27 Presley Way, Crownhill, Milton Keynes MK8 OES, UK; nbrooks@rww.org.uk

\section{REFERENCES}

1 Newcombe F. Very late outcome after local wartime brain wounds. J Chin Exp Neuropsychol 1996;18:1-23.

2 Walker AE, Blumer D. The late and World War II veterans with posttraumatic seizures. Arch Neurol 1989;46:23-6.

3 Corkin S, Rosen TJ, Sullivan EV, et al. Penetrating head injury in young adulthood exacerbates cognitive decline in later years. Nerosci 1989:9:3876-83. 4 Plassman BL, Havlik R, Steffens DC, et al. and risk of Alzheimer's disease and other dementias. Neurology 2000;55: 1 158-66.

5 Millar K, Nicoll JAR, Thornhill S, et al. Long term neuropsychological outcome after head injury: relation to APOE genotype. J Neurol Neurosurg Psychiatry 2003;74:1047-1052.

\section{Spinal cord atrophy and disability in multiple sclerosis over four years}

\section{A Horsfield, M Filippi}

\section{A reproducible measure of cord area for detecting atrophy rates}

t is natural to focus on spinal cord damage as a major factor in disability. Indeed, interest in the use of MRI to study the spinal cord in multiple sclerosis, and its relation to locomotor disability, has been on the increase for over 10 years. The paper by Lin et al (pp 1090$1094)^{1}$ is the first medium term follow up (four years) of spinal cord atrophy in both untreated patients and patients treated with interferon $\beta$-la.

Initial studies of the cord concentrated on the visible lesions seen with conventional MRI, and results were perhaps disappointing, with little direct influence of acute and chronic damage as seen on conventional T2 weighted scans. More recently, with methods capable of detecting more subtle abnormalities such as magnetisation transfer imaging or $\mathrm{Tl}$ mapping, stronger correlations (albeit still weak) with expanded disability status scale (EDSS) scores are emerging. ${ }^{2}$ It is thought that, in addition to macroscopic lesions located in the cord, repeated acute insults in the central nervous system cause Wallerian degeneration and axonal loss; this can extend to the cord-whether the primary site is in the cord or the cerebrum - and while the damage is not seen as a focal lesion, rarefaction of the axons nevertheless occurs throughout the cord, leading to diffuse pathological changes and cord atrophy. Atrophy of the cord may therefore be another important indicator of disease progression, and of the impact of the disease on a major contributor to disability and quality of life. Indeed, cord atrophy appears to be greater 
in the progressive forms of multiple sclerosis, although it can be observed even in patients at the earliest clinical stage of the disease. ${ }^{4}$ Measurements of cord atrophy rates might make an important contribution to the long term evaluation of therapeutic efficacy of new treatments for multiple sclerosis, especially in primary progressive disease.

Unfortunately, treatment with interferon $\beta$ and other compounds has thus far been shown to have little effect on cerebral atrophy. As atrophy is likely to be the end result of acute events that may have happened some time ago, the problem may be that short term follow up (a few years) is insufficient to show any long term benefit of treatment. Alternatively, it could be that some underlying damaging process is still ongoing, even when acutely disabling events are suppressed by treatment. The paper by Lin et al extends finding in the cerebrum to the spinal cord, and adds to this disappointment. Despite using what is clearly a very reproducible measure of cord area, capable of detecting low atrophy rates, the rate seems to have been unmodified by interferon $\beta$-la treatment. There have been several recent studies (including Lin's) showing a correlation between cerebral and cord atrophy rates and EDSS score at follow up, $^{5}$ so the importance of slowing atrophy is not in doubt. The remaining question is whether any of the existing treatments, or putative new ones, will have an impact on the disabling aspects of multiple sclerosis in the long term.

J Neurol Neurosurg Psychiatry

2003;74:1014-1015

Authors' affiliations

M A Horsfield, Division of Medical Physics, University of Leicester, Leicester Royal Infirmary, Leicester LE1 5WW, UK

M Filippi, Neuroimaging Research Unit,

Scientific Institute Ospedale S Raffaele, Via

Olgettina 60, Milan, Italy
Correspondence to: Mark A. Horsfield; mah5@le.ac.uk

\section{REFERENCES}

1 Lin X, Tench CR, Turner B, et al. Spinal cord atrophy and disability in multiple sclerosis over four years: application of a reproducible automated technique in monitoring disease progression in a cohort of the interferon $\beta$-1 a (Rebiff) treatment trial. J Neurol Neurosurg Psychiatry 2003;73:1090-4.

2 Rovaris M, Bozzali $M$, Santuccio $G$, et al. In vivo assessment of the brain and cervical cord pathology of patients with primary progressive multiple sclerosis. Brain 2001;124:2540-9.

3 Bergers E, Bot JC, De Groot CJ, et al. Axonal damage in the spinal cord of MS patients occurs largely independent of T2 MRI lesions. Neurology 2002:59: 1766-71.

4 Brex PA, Leary SM, O'Riordan Jl, et al. Measurement of spinal cord area in clinically isolated syndromes suggestive of multiple sclerosis. I Neurol Neurosurg Psychiatry 2001:70:544-7.

5 Paolillo A, Pozzilli C, Giugni E, et al. A 6-year clinical and MRI follow-up study of patients with relapsing-remitting multiple sclerosis treated with interferon-beta. Eur J Neurol 2002;9:645-55.

HISTORICAL NOTE.

\section{Cruveilhier and acoustic neuroma}

S ome 20 years after the first observations published on neuromas (William Wood in 1828), ${ }^{1}$ Robert William Smith published his treatise on neuromas, ${ }^{2}$ which included a full description of von Recklinghausen's multiple neurofibromatosis. ${ }^{3}$ But the year 1592 may be the first in which a person with neurofibromatosis was described. ${ }^{4}$

In the Medical Transactions of the Royal College of Physicians, London, forerunner of the JRCP, Mark Akenside (1721-70), gave a recognisable account of multiple neurofibromatosis. The acoustic neuroma may be symptomatic of NF2 but, more often is a solitary schwannoma. One of the earliest illustrations is to be found in Cruveilhier's classic two volume atlas (vol 1 1835, Vol 2 1842). ${ }^{6}$ Jean Cruveilhier (1791-1874) was the first professor of pathological anatomy in Paris and the first to describe the white matter plaques in multiple sclerosis. ${ }^{7}$ Spillane $^{8}$ regarded Cruveilhier as "the prince of these physician-pathologists". His excellent illustration (livraison 26, Plate 2$)^{8}$ shows a large nodular left cerebello-pontine mass in a 26 year old woman whom Cruveilhier attended in the last three months of life. The onset he relates, was with headaches and she lost her hearing from the age of 19. At 20, there was impairment of vision in the right eye; at 21, involuntary twitching of the left cheek. Vision worsened and she became blind and in her last year, the convulsive movements of the left side of her face became stronger and more frequent and spread accompanied by spasms of rigidity of the arms. There developed tingling in the left cheek and increasing headache. Cruveilhier's examination showed no paralysis and "she got up every day" until the last month. He diagnosed a meningeal tumour compressing the brain and thought it was situated at the base.

At autopsy, he found a large tumour in the posterior fossa compressing brain stem and cerebellum, with bilateral optic atrophy and involvement of the cranial nerves V to XI. It was adherent to the back of the left petrous bone and had eroded the internal auditory meatus.

Curiously, ataxia is not described, but this may have been overlooked, or masked by her blindness. ${ }^{8}$ The compression of the facial nerve suggests that Cruveilhier's patient may have been one of the first to have facial myokymia.

\section{J M S Pearce \\ 304 Beverley Road, Anlaby, Hull HU10 7BG; jmspearce@freenet.co.uk}

References

1 Wood W. Observations on neuroma. Trans Med-Chir Soc Edin 1828-29;3:367-433.

2 Smith RW. A treatise on the pathology, diagnosis and treatment of neuromas. Dublin: Hodges and Smith, 1849.

3 von Recklinghausen FD. Über die multiplen fibrome der haut und ihre beziehung zu den multiple neuromen. Berlin: Hirschwald, 1882. (Crump T. Translation of case reports. Adv Neurol 1981;29:259-75.)

4 Aldrovandi, J. Monstrorum historia cum paralipomenis historiae omnium animalium, bononiae. Typis Nicolai Tibaldini, 1642. (Cited by Riccardi VM, Koehler PJ. In: Koehler P, Bruyn G, Pearce JMS. Von Recklinghausen's disease. Neurological eponyms. New York, Oxford University Press, 2000:357-65.)

5 Akenside M. Observations on cancers. Transactions of the Royal College of Physicians, London 1786;1:64-92.

6 Cruveilhier J. L'Anatomie pathologique du corps humain; descriptions avec figures lithographiées et coloriées: diverses alterations morbides dont le corps humain est susceptible. Vol 2; Liv 32, PI 2, pp 19-24; Liv 38, PI 5, pp 1-4. Paris: Baillière, 1829-42.

7 Pearce JMS. Some British contributions to the history of multiple sclerosis. J Neurol Neurosurg Psychiatry 1989;52:303.

8 Spillane JD. The doctrine of the nerves. Oxford: Oxford University Press, 1981:205-11. (Spillane gives a fine reproduction of livraison 26, Plate 2. and provides the clinical history. 